\title{
A Cultural Survey of Technological Innovation from the Perspective of SST
}

\author{
WANG Rui ${ }^{1}$ \\ WANG Xiao-yu ${ }^{2}$ \\ LI Peng ${ }^{3}$
}

'Professor, Doctor, school of law \& art, Shenyang University of Technology, P.R. China

${ }^{2}$ Doctor, school of Architecture \& Civil Engineering, Shenyang University of Technology, P.R. China ${ }^{\circ}$ Doctoral student, school of Marxism, Northeastern University, P.R. China

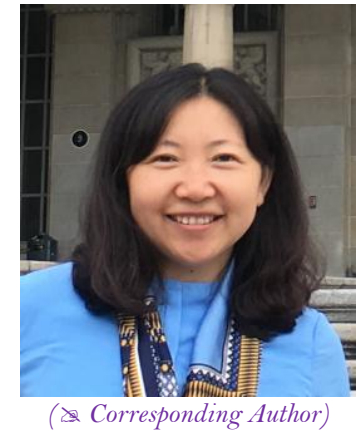

(4) Check for updates

\begin{abstract}
Technological innovation and society are interrelated. Therefore, only in the opposing and unified social practice to grasp the technological innovation, and only the technological innovation itself as a cultural practice to understand the process of technological innovation. In the perspective of the social shaping of technology, Technological innovation is a cultural choice. Technological innovation proceeds in hardship in the social culture. Technological innovation implementation in the choices of multi-culture conflict. Guidance of technological innovation subject values for technological innovation behavior. In this sense, technological innovation has become a process developing and utilizing "new technology" to construct "new society", The interaction between technological innovation and society creates a new culture-technological innovation culture.
\end{abstract}

Keywords: Technological innovation, Cultural survey, Technological innovation culture, SST.

\section{Introduction}

According to relevant information, the average life expectancy of Chinese enterprises is only ten years. This phenomenon shows that a considerable number of enterprises in China in the long-term development of its competitiveness and viability is declining, the ability of continuous innovation is not enough, lack of motivation.

On the surface, this phenomenon is the business management problems, but it is fundamentally a cultural problem, that is, from the date of the establishment of the enterprise did not put technological innovation as a cultural issue to deal with.

Therefore, China's technological innovation is a cultural issue. In the perspective of the social shaping of technology, Technological innovation culture is the cultural phenomenon formed in the practice of technological innovation, and is guided by the values of technological innovation.

However, due to the limitations of the research perspective, the theoretical circles can not carry out in-depth and comprehensive research on the cultural problems of technological innovation, so as to affect the effective development of technological innovation practice in China.

\section{Technological Innovation is a Cultural Choice}

In the SST perspective, scholars believe that technical systems include technical, economic, organizational, political and cultural aspects. Social factors and cultural factors have always affected the implementation and efficiency of technological innovation.

According to Basara, because of the technology innovative capability's excess, there could be an incomplete conjunction between the invention and the need, or between different needs. Thus, a process of choosing is bond to happen, with some developed and absorbed in a culture, while others shut down. The chosen inventions are copied and merged into the mainstream of artificial products, therefore stimulate the birth of a new generation variety of this artificial product.

As for those rejected inventions, they could make very little difference to the future artificial world unless someone brings them back to this mainstream on purpose [1].

Hence, not all inventions can become innovative products, and technological innovations are not bond to happen. It is like biological evolution which embodies the law of nature selection. Whereas the fundamental difference between human evolution and biological evolution is that one of them is chosen by nature, and the other is by human beings, i.e. by cultures. 


\section{Technological Innovation Proceeds in Hardship in the Social Culture}

As far as the developing history of technological innovation is concerned, its development is bound by the material life especially the spiritual life in the certain era. Whether technological innovation can be accepted by the society depends on the cultural environment of certain eras, including the recognition of technological innovation by people's concept of value and value orientation, etc.

That is to say that the creation and development of technological innovation can only be accomplished under the social culture backdrop. According to Rapp," technology development is always tangled with intellectual background: the latter is formed during the historical development and determines the future development of technology."

Hence, "each era has its own definition on the relationship between the era and technology." The spiritual culture foundation of modern European technology includes: (1) the evaluation of labor; (2) effective management; (3) the stimulation on technological creativeness; (4) rationalism and enlightenment; (5) objectification of the nature; (6) mechanistic concept of nature; (7)mathematical methods; (8) eight aspects of experimental research [2].

Besides, technological innovation can only proceed in the direction which has least cultural resistance when technical specification is in conflict with social culture.

According to statistics of major scientific and technological results from 1501 to 1950 in the book Fasti of Science and Technology written by a Japanese scholar Mintomo Yuasa, countries whose scientific and technological results are more than $25 \%$ of the global total are called "scientific and technological activity center", and this era is called a flourishing time of science and technology.

In accordance with this standard, there are five major transfers of the "scientific and technological centers" since recent times, which are Italy (1504-1610) — British (1660-1730) — France (1770-1830) — Germany (18101920) — the United States (1920 till now) [3].

All transfers of the scientific and technological center have one thing in common, that is a sound humanistic environment.

The series encouraging policies adopted by the UK including establishing royal academy; the Enlightenment and the liberal policy that abolished the block; the philosophical tradition that's famous in Germany, and the free environment that attracts talents in the US, all of them have shown a open policy, dynamic economy, sound humanistic environment and the interaction, which is decisive to technology development.

Merton once pointed it out that "The explicit utilitarianism, the interests on mundane world, the systematically, unremitting action, the downright empiricism, the right and responsibility to do free researches and the anti-traditionalism of Puritanism, the combination of which is consistent with the same value concept in science."

Hence, "The culture in the $17^{\text {th }}$ England is very conducive to the growth and spreading of science and technology" [4]. We can see that the major development of science and technology in the $17^{\text {th }}$ England has direct connection with the recognition by the then religious culture.

\section{Technological Innovation Implementation in the Choices of Multi-Culture Conflict}

Judging from the appereance, technological innovation is the result of innovative subject acting on the innovatce object through some innovative medium, while in fact it is the choice made in the multiculture conflict. For example, all links in conception, demonstration, evaluation and experiment of the technology designing plan are done through constant comparison and choices.

For instance, the Three Gorges Project has been through arduous demonstration and choices for half a century. In the recent century of medical practice where Western medicin, traditional Chinese medicine, Tibetan medicine and other medical technologies coexsit, the expansion of Western medicine and the shrinking of traditional Chinese medicine are the results of social cultural choice of consciousness [5].

The realisation of new technology innovative projects inside an enterprise include innovation decisions, innovation $\mathrm{R} \& \mathrm{D}$, productive technological innovation, market innovation, management innovation and many other links. During each link, there are choices to make from many possibilities. When people or group holding different ideas from different cultural background while are receiving the same culture gather together, the social culture, enterprise culture, group culture and personal culture will adjust and control the development of technological innovation. Related innovative subjects such as enterprises, public institutions, universities, scientific research institutions, and individuals can choose according to their own cultural background.

People from different cultural background are certain to have conflicts sometimes. And the cultural conflict not only embodies in the relationship between employees in the same enterprise, but also between the employees in the enterprise and people from outside. If the differences and conflicts are too obvious, there would be a negative impact on technological innovation. They have to either abort the technological innovation activity, or do it in other organizations [6].

On the organization level, the members in the organization will influence the behavior of innovative subject by establishing sharing culture according to the social cultural background. For example, when talking about improving innovation performance, the national innovation systematic theory of OECD pointed it out that technological innovation is the result of a series of complicated interactions of actors produce, distribute and apply all kinds of knowledge in economic actions.

Hence, the innovation performance is highly dependent on the way the actors (people who work in private enterprises, universities, public research institutions) contact with each other. That is to say that whether the innovation subject can realize the exchanging and communication of cooperative research, personal exchanges, patent pool, purchasing equipment, etc. as well as who the innovation subject will choose to be the partner, these are much influenced and decided by the organization culture. 
On the society level, to decide whether a technological innovation is successful is highly dependent on how much the society accept it, recgonize it and retribute it. While besides the most foundamental needs, there are still spiritual levels of culture including national tradition, customs, religions and emotional patterns among the complicated elements that form the market.

To gain the market, when forming innovation concept and ideas, technological innovation have considered the need of the market and what kind of ideas are realistic and can target the right comsumers accurately.

During the popularizition, the market psychology formed by social culture, enterprise culture, group culture and personal culture even can decide whether the innovation is successful directly [7]. Hence, the successful implementation of technological innovation is not a simple combination of individual and organization behaviors, but the efficient "coordination" by many participetors from various cultures.

\section{Guidance of Technological Innovation Subject Values for Technological Innovation Behavior}

The difference between practice and cognitive activities is that cognitive activities are from material to feeling and then to thoughts, whereas practice is thoughts first and then being transferred to actions. To be specific to the implementation level of technological innovation is to translate innovative ideas to behavioral direction and material form guiding human beings to operate successfully. This conversion process is based on a certain psychological basis.

Therefore, technological innovation practice is a process of recognition, selection and acceptance of technological innovation and its consequences, and also an internal value pursuit made by innovation subject to express its value orientation as well as values through technological innovation practice. The pursuit of value itself is a cultural behavior with cultural features of individual intent and environmental convergence.

The quality and quantity of technology determines its value range. Within the value range of technology, there exists a variety of potential values, constituting technology representation from different level. With different detailed means for using technology, the potential value of a technology can only be presented to different realistic values of technology gradually.

Due to opposite interests of various groups, or changes of demand of the same group in different period, the same technology often shows different and even diverse realistic values in different specific application processes. This leads to what we normally call technological value division, namely, a phenomenon that the same technology can be used for good and for evil [8].

Generally speaking, the difference of cultural features is an important factor in deciding the direction for technology development.

For example, a nation with curiosity is beneficial to technological development, and a nation with craftsmanship, enterprising spirit, perfection seeking and other features is also of great benefit. Different cultural feature also differs in technological development demand. For instance, a culture known for technology and reason has a high demand for technology development, whereas the culture dominated by humanism does not generate this demand spontaneously.

Therefore, we can say that values of technological innovation subject had played a guiding role for development direction of technological innovation culture. Values of technological innovation subject reflect more as motivation when the subject conduction technological innovation.

When technological innovation subject conducting a technological innovation practice, it would carry out innovation in accordance with its own innovation expectation and individual preference, to make it a way to achieve its innovation goals.

This process contains intentionality of individual cognition, understanding and assessment of technological innovation, as well as multi-cultural choices. Meanwhile, technological innovation subject's degree of recognition for technological innovation products would also decide the effect technological innovation activities can achieve.

\section{Conclusions: A New Culture Type-Technological Innovation Culture}

As what mentioned before, technological innovation is a reciprocating process in which it conducting material energy exchange with social culture continuously.

Technological innovation's cultural change and renewal effect for modern society development mainly achieved by the process of occurrence and acceptance of cultural demonstration effect formed by technological innovation. The reason why this cultural demonstration effect occurred and is being accepted is essentially owing to the regulation of culture.

The processes in which some technical solutions are occasionally and repeatedly used are being imitated, repeated and spread in society just like similar belief, buzzwords, fashion and other cultural expression items [9]. That means, when a society achieved technological innovation successfully and thus led to its enormous advantages at the technological and economic development level, the accompanying culture then had a high degree of vitality control, internalizing values and behavior patterns which are specific in technological innovation activities into culture.

These values and behavior patterns can stimulate members' creative potential, attitudes of willingness to take risks and active participation, as well as coordinated behavior, to flexibly coping with complex and volatile external environment. In this sense, technological innovation has become a process developing and utilizing "new technology" to construct "new society". The joint development between technological innovation and culture would produce a new cultural type-technological innovation culture [10].

\section{References}

Basara, The evolution of technology [M] Zhou Guangfa trans: Fudan University Press, 2000

F. G. Rapp, Introduction to philosophy of technology $[M]$. Shenyang: Liaoning Science and Technology Publishing House, 1986. Wangfei and L. Wang, "Internal driving force of cultural innovation and knowledge-based economy [J]," Fujian BBS Humanistic and Social Science Edition, vol. 11, p. 161, 2006. 
[4] M. K. Robert, Science, technology and society in seventeenth century England [M]. Beijing: The Commercial Press, 2000.

B. Wang, Culture remodeling in the Era of technicalization $[M]$ vol. 3. Beijing: Guangming Press, 2014.

G. Hu and F. Yan, "The cultural integration of technological innovation $[\amalg]$," Journal of Social Science of Hunan Normal University, vol. 35 , pp. 87-89, 2006.

Z. Xu, "The dialectical relationship between innovation and culture [J]," Scientific Management Research, vol. 9, p. $20,2002$.

$\mathrm{H}$. Li, Humanistic conflict and integration of modern technology $[M]$. Beijing: China Market Press, 2004.

Arthur, The nature of technology: What it is and how it evolves [M]. Cao Dongming $\mathcal{E}^{2}$ Wang Jian trans vol. 4. Hangzhou: Zhejiang People's Press, 2014.

[10] Wangrui, The culture of technological innovation theory [M]. Beijing: Normal University Publishing Group, 2012.

Citation | WANG Rui; WANG Xiao-yu; LI Peng (2017). A Cultural Survey of Technological Innovation from the Perspective of SST. International Journal of Social Sciences and English Literature, 1: 1-4.

History:

Received: 16 February 2017

Revised: 3 March 2017

Accepted: 8 March 2017

Published: 11 March 2017

Licensed: This work is licensed under a Creative Commons

Attribution 3.0 License (oc)

Publisher: Eastern Centre of Science and Education
Contribution/Acknowledgement: All authors contributed to the conception and design of the study.

Funding: This work was financially supported by National Social Science Foundation of China (12CZXo19, National Natural Science Foundation of China (51208309, Liaoning BaiQianWan Talents Program, Liaoning province Department of Education fund (WGD2016011, Liaoning Provincial Association for science and technology projects（LNKX2016C27）

Competing Interests: The authors declare that they have no conflict of interests.

interests.

Transparency: The authors confirm that the manuscript is an honest, accurate, and transparent account of the study was reported; that no vital features of the study have been omitted; and that any discrepancies from the study as planned have been explained.

Ethical: This study follows all ethical practices during writing.

Eastern Centre of Science and Education is not responsible or answerable for any loss, damage or liability, etc. caused in relation to/arising out of the use of the content. Any queries should be directed to the corresponding author of the article. 